\title{
CORANTES TÊXTEIS: UMA REVISÃO
}

\section{F. Peixoto', G. Marinho ${ }^{2}$ e K. Rodrigues ${ }^{3}$}

${ }^{1}$ Mestranda em Tecnologia e Gestão Ambiental-Instituto Federal do Ceará

${ }^{2}$ Pró Reitoria de Pesquisa e Inovação - Instituto Federal do Ceará

${ }^{3}$ Laboratório de Tecnologia Ambiental-Instituto Federal do Ceará

Email: fpinho@ifce.edu.br ${ }^{1}$; gloriamarinho@gmail.com ${ }^{2}$; kelly@ifce.edu.br ${ }^{3}$

Artigo submetido em janeiro/2013 e aceito em outubro/2013

\section{RESUMO}

A indústria de corantes desenvolve um importante papel na economia do mundo, visto que estes são utilizados em várias atividades fabris. Os corantes têxteis causam especial impacto no meio ambiente principalmente por serem de difícil degradação. Vários processos tem sido estudados a fim de que se consiga realizar um tratamento realmente efetivo em remoção de corantes de efluentes têxteis, entre eles os processos biológicos estão recebendo uma particular atenção por sua eficiência. O tratamento microbiológico de efluentes, especialmente por espécies fúngicas tem ganhado espaço, por estes organismos serem bastante versáteis, tratarem uma grande variedade de tipos de corantes e apresentarem diferentes mecanismos de remoção de cor. Portanto os fungos apresentam-se bastante atrativos e demonstram serem os organismos mais adequados em relação a tratamento de efluentes têxteis.

PALAVRAS-CHAVE: Efluentes têxteis, Corantes, Fungos, Biossorção, Biodegradação.

\section{TEXTILE DYES: A REVIEW}

\section{ABSTRACT}

The dye industry plays an important role in the world economy, since these are used in various industrial activities. The textile dyes cause particular impact on the environment mainly because they are difficult to breakdown. Several processes have been studied in order that they can make a truly effective treatment for removal of dyes from textile effluents, including biological processes are receiving special attention for its efficiency. The microbiological treatment of wastewater, especially for fungal species has gained space for these organisms are quite versatile, treating a wide variety of colors and have different mechanisms of color removal. So fungi have become quite attractive and shown to be more appropriate in relation to the treatment of textile effluents.

KEYWORDS: Textile effluents, Dyes, Fungi, Biosorption, Biodegradation. 


\section{CORANTES TÊXTEIS: UMA REVISÃO}

\section{INTRODUÇÃO}

Vários corantes são usados nas indústrias têxteis, alimentícia, de fabricação de papel e na indústria cosmética[25]. Estes corantes, em especial os corantes têxteis, são considerados extremamente perigosos devido sua toxicidade e por apresentarem baixa taxa de degradabilidade.

O esgoto da indústria têxtil tem sido taxado como o mais poluente entre os setores industriais em termos de volume e composição de efluentes ([31], [56]). Em adição ao efeito visual e ao efeito adverso dos corantes em termos de impacto de Demanda Química de Oxigênio (DQO), muitos corantes são tóxicos, mutagênicos e carcinogênicos ([1], [44]).

Corantes em tecidos são projetados para serem resistentes, por exemplo, à luz Ultra Violeta, e por isso constituem um grupo desafiante de compostos químicos quando se trata de processos degradativos [38].

Numerosos processos têm sido propostos para o tratamento de efluentes coloridos como precipitação, floculação, coagulação, adsorção e oxidação ([10], [21]). Esses processos em geral são caros e possuem eficiência limitada além de gerarem um resíduo que também necessita de tratamento.

Tem crescido o interesse por processos biotecnológicos que visem diminuir o alto custo do tratamento destes efluentes e que sejam realmente eficientes [25].

Muitos fungos e bactérias são usados para o desenvolvimento dos processos biológicos para o tratamento de efluentes têxteis ([2], [17]).

O número de pesquisas em relação aos fungos tem crescido a cada ano devido estes organismos serem pouco seletivos e facilmente adaptáveis ao meio.

Muitos estudos de descoloração têm sido feitos usando-se os fungos da podridão branca, tais como Phanerochaete chrysosporium, Bjerkandera adusta, Trametes versicolor ou Phlebia radiata, que se mostram hábeis em degradar um amplo espectro de corantes.

As atuais pesquisas giram em torno de tecnologias que empreguem materiais mais baratos e visam uma remoção mais eficiente sem gerar outros resíduos pós tratamento.

\section{Caracterização de Efluentes Têxteis}

A produção total de corantes no mundo é estimada em 800.000 ton./ano e pelo menos $10-15 \%$ destes entram no meio ambiente através dos efluentes ([42], [48]).

Efluentes contendo corantes têxteis são geralmente descartados em grande quantidade no mundo todo em corpos de águas naturais diariamente [34]. Corantes são identificados como os compostos mais problemáticos nos efluentes têxteis devido a sua alta solubilidade na água e baixa degradabilidade ([8], [55]).

Uma vez no meio ambiente, os corantes podem mostrar sua toxicidade e efeitos 
genotóxicos nos organismos [58].

$\mathrm{Na}$ falta de alguma regulamentação governamental específica de disposição desses corantes, o problema se mostra como a principal dificuldade em relação às atividades têxteis e o meio ambiente [37].

O principal problema citado está a não biodegradabilidade destes efluentes, não só pelos corantes, mas também devido a outros componentes adicionados aos processos como surfactantes e aditivos. As composições das soluções coloridas contem corantes reativos hidrolisados, substanciais quantidades de álcalis e alta concentração de cloreto de sódio [7].

Em geral um efluente típico de uma indústria têxtil de algodão é caracterizado por altos volumes de Demanda Química de Oxigênio (DOQ), Demanda Bioquímica de Oxigênio (DBO), cor e $\mathrm{pH}[22]$.

Os corantes reativos são altamente solúveis em água devido a moléculas poliaromáticas, o que significa que sua adsorção em sólidos é relativamente pobre [18].

Corantes têxteis são geralmente resistentes à degradação microbiana [58].

Além dos grupos substituintes que permitem a fixação de corantes nas fibras, a molécula de corante uma estrutura aromática que absorve a luz (grupo cromogênico) [37].

A taxa volumétrica extremamente alta de efluente industrial descartada em combinação como o aumento do rigor da legislação, faz a pesquisa de tecnologias apropriadas de tratamento uma prioridade ([50], [57]).

\section{Tratamentos Mais Utilizados}

\subsection{Físico-Químicos}

A eliminação de substâncias coloridas no efluente é baseada principalmente em métodos físicoquímicos [9]. Não há um método universalmente utilizado para o tratamento de efluentes têxteis, provavelmente por causa da variedade de estruturas químicas e complexidade desses compostos [43]. A eficiência dos processos oxidativos avançados (POAs) para a degradação de compostos recalcitrantes tem sido extensivamente documentada [37].

Processos fotoquímicos são usados para degradar compostos tóxicos para $\mathrm{CO}_{2}$ e $\mathrm{H}_{2} \mathrm{O}$ sem o uso de oxidantes adicionais, pois a degradação é assistida por altas concentrações de radical hidroxil. Neste caso a foto excitação de partículas do $\mathrm{TiO}_{2}$ promovido de uma banda de valência para a banda de condução gerando o par elétron/vacância [37].

O ozônio é um poderoso agente oxidante quando comparado com outros agentes oxidantes conhecidos como $\mathrm{H}_{2} \mathrm{O}_{2}$ e pode reagir com diferentes classes de corantes através de reações diretas e indiretas [37].

Os grupos cromóforos geralmente são orgânicos com ligações duplas conjugadas que podem ser quebradas pelo ozônio formando pequenas moléculas cujo resultado é a redução à cor do efluente ([29], [33]). Todos esses métodos têm diferentes capacidades de remoção de cor, custos e rapidez de operação. Entre esses métodos, coagulação e adsorção são comumente utilizadas, entretanto eles geram enormes quantidades de lodo que se tornam um problema em termos de descarte [39]. Todas essas técnicas têm deficiências, então uma alternativa barata e efetiva deverá ter grande valor [60]. 


\subsection{Biológicos}

Os tratamentos biológicos para descoloração e degradação de efluentes têxteis podem ser aeróbios e anaeróbios, ou uma combinação de ambos, dependendo do tipo de microrganismos que estão sendo empregados [10].

A literatura sugere que há um grande potencial de desenvolvimento de sistemas microbiológicos de descoloração, com total remoção de cor, em alguns casos, em poucas horas ([8], [32]). Corantes têxteis são relativamente resistentes à degradação microbiana, desta forma, não é surpresa que apenas uma pequena parte seja degradada nos sistemas de lodos ativados, já que estes corantes são projetados para resistir à degradação [58]. Assim, sistemas convencionais de lodos ativados são claramente ineficientes em descolorir efluentes têxteis, a menos nos casos em que sejam misturados e tratados junto com esgoto [58].

É sabido que micro-organismos anaeróbicos são hábeis em degradar alguns corantes com a desvantagem da produção de aminas aromáticas que podem ser tóxicas e carcinogênicas [35].

A digestão anaeróbia de efluentes têxteis é uma tecnologia muito promissora desde que se aliando eficiência, custo e segurança ambiental [7]. Bactérias geralmente são culturas fáceis e crescem mais rapidamente do que os fungos. São hábeis ao se fazer manipulação genética. São capazes de metabolizar compostos clorados e contaminantes orgânicos como óleos e mineralizar substâncias químicas usando carbono e nitrogênio como fontes de energia [7]. As bactérias também podem ser aplicadas em um consórcio microbiano misto para descoloração de corantes abaixo das condições anaeróbias.

Em vários estudos prévios uma mistura de culturas bacterianas teve melhor atividade de descoloração em condições anaeróbias em meio ricamente suplementado com extrato de levedura ou glicose ([13], [41]). Contudo, esses substratos usados em laboratório não são adequados para aplicação in situ [12]. À proporção que o corante é degradado geram-se aminas tóxicas [19], então, não é recomendado o tratamento anaeróbio sem um subsequente tratamento aeróbio onde esses componentes possam ser oxidados ([30], [40]). Enquanto muitos estudos são dedicados à biodescoloração de corantes têxteis, muito pouca atenção tem sido dada às soluções de corantes têxteis quanto à presença de sais e de altas concentrações de diversos constituintes que pode ser inibitória aos agentes biológicos [36].

\section{Remoção de Corantes por Fungos}

Os fungos tem provado serem os organismos mais apropriados para o tratamento de efluentes têxteis e remoção de corantes [24]. Em anos recentes, muitos estudos tem demonstrado que os fungos são capazes de descolorir e remover corantes têxteis por biossorção ([4], [59]). Muitos fungos tem capacidade de descolorir efluentes industriais contendo corantes via adsorção de biomassa sem degradação ou através de degradação aeróbia completa [52].

Os fungos podem ser aplicados para esses processos tanto na forma in vivo como imobilizados e muitos gêneros tem sido empregados para descoloração de efluentes.

Os fungos promovem a remoção de corantes de efluentes têxteis principalmente através de três mecanismos: biossorção, bioacumulação e biodegradação.

\subsection{Biossorção}


Hoje, o que mais se observa em termos de pesquisa de adsorção é a procura por adsorventes de baixo custo, assim, tem crescido o interesse pelos resíduos da indústria ou da agricultura, além de biomassa microbiana como bactérias, fungos e algas podem ser utilizados como material adsorvente.

A biossorção pode ser definida como uma ligação do soluto à biomassa através de um processo que não envolve transporte de energia metabólica, embora cada processo possa ocorrer simultaneamente quando biomassa viva é utilizada [24].

Recentemente, muitas pesquisas têm mostrado que a biossorção pode ser considerada como uma alternativa válida aos métodos físico-químicos e/ou a degradação enzimática ou microbiológica [46].

Entre os diversos tipos de biomassa pesquisada, os fungos tem mostrado ser particularmente apropriados para este processo [46].

A referência [17] descreve um estudo em que o Aspergillus níger foi capaz de remover corantes de uma solução aquosa e a biossorção foi influenciada pelos grupos funcionais da biomassa fúngica e da estrutura química dos corantes.

Atualmente, entre as numerosas técnicas de remoção de corantes, a biossorção através de carbonos ativados ou resinas orgânicas é o procedimento que mostra os melhores resultados e pode ser usado para remover diferentes tipos de materiais coloridos, apesar de ter alto custo, o que aponta a necessidade de encontrar materiais biossorventes menos caros ([14], [20]).

\subsection{Bioacumulação}

Bioacumulação é o acúmulo de poluentes por ativação de células em crescimento por seu metabolismo [2]. A referência [2] mostra um estudo sobre a bioacumulação dos corantes reativos Remazol Blue, Reactive Black and Reactive Red por uma levedura da espécie Candida tropicalis crescendo em melaço e foi descoberto que o aumento da concentração de corante inibiu o crescimento da levedura e produziu um período "lag" muito longo, período no qual em que o microrganismo está se adaptando ao novo meio e pode não ocorrer multiplicação celular.

\subsection{Biodegradação}

A biodegradação é um processo dependente de energia e envolve a quebra dos corantes através da ação de várias enzimas [24]. A quebra completa das moléculas orgânicas com a produção de água, dióxido de carbono ou outros produtos inorgânicos é chamada de mineralização.

A biodegradação de corantes por certos grupos de fungos durante a remoção de cor tem sido largamente demonstrada [24]. A degradação e a mineralização de corantes é efetiva por certos grupos de fungos da podridão branca (FPB).

Os fungos da podridão branca podem degradar uma grande variedade de diversos poluentes ([11], [23]). Este grupo fisiológico de organismos toma parte do ciclo do carbono como resultado da sua habilidade em degradar lignina, a segunda fonte mais renovável e largamente distribuída na biosfera ([45], [47]). A descoloração de azo, antraquinonas, heterocíclicos, trifenilmetano e corantes poliméricos e sua parcial mineralização por sistemas enzimáticos e não enzimáticos dos FPB tem sido amplamente demonstrada ([15], [16], [53]).

Os FPB são os únicos entre os organismos eucarióticos e procarióticos que possuem um poderoso 
sistema enzimático oxidativo, a enzima lignina-degradadora (ELD) [49].

A falta de seletividade desta enzima considerando os compostos aromáticos que são atacados é a justificativa para o interesse de se usar os FPB também para aplicação em efluentes têxteis [38].

Seu sistema lignolítico extracelular envolve enzimas como Manganês peroxidade (MnP), Lignina peroxidade (LiP) e Lacase (Lac) que são envolvidas não só na degradação de lignina, mas também na degradação de compostos xenobióticos, incluindo corante, pesticidas, compostos bifenilpoliclorados (BPCs) e compostos hidrocarbonetos aromáticos policíclicos (HAPs). ([26], [45]).

Condições de cultura podem afetar a atividade das enzimas lignolíticas destes fungos.

Culturas estáticas têm sido reportadas serem necessárias para a atividade das enzimas lignolíticas e agitação das culturas leva ao decréscimo da atividade enzimática [27].

Culturas estáticas de $T$. versicolor e $P$. chrysosporium mostraram sucesso na degradação de xenobióticos ([6], [51]). Contudo, culturas agitadas de um grande número de fungos mostraram que a agitação resultou em uma melhor descoloração ([27], [53]). A eficiência do processo de descoloração pode ser melhorada cuidadosamente selecionando as condições operacionais como adição de cossubstratos adequados no meio de cultura, especialmente carbono, nitrogênio e micro-elementos [5].

\section{Conclusões}

As pesquisas em torno de remoção de corantes de efluentes têxteis têm crescido dia a dia, e novos métodos têm sido apresentados, visando um tratamento que tenha uma boa relação custo benefício. Contudo, ainda há grandes impasses, pois as técnicas propostas para o tratamento desses efluentes geralmente são caras e não oferecem uma remoção satisfatória. Nesse contexto os tratamentos biológicos têm sido indicados, apesar de os corantes têxteis serem bastante resistentes. Os tratamentos anaeróbios e aeróbios são geralmente utilizados em combinado, o que demanda um elevado custo. Os fungos, especialmente os fungos da podridão branca tem-se se mostrado como os mais indicados para essa função, por secretarem enzimas que degradam a lignina e vários estudos tem demonstrado sua eficiência em uma larga gama de corantes e com variadas espécies de fungos.

As pesquisas recentes mostram que os fungos tem um importante papel na remoção de corantes nos efluentes têxteis, independente do mecanismo que utilizem para fazê-lo, porém, novos estudos devem ser realizados para o desenvolvimento dessa técnica, entendendo que os estudos foram realizados totalmente em escala laboratorial, devem ser buscadas as condições ótimas para que isso aconteça e as espécies mais indicadas para cada corante em particular e, posteriormente, uma espécie que degrade com eficiência, com um custo mais baixo, uma estação de tratamento real.

\section{REFERÊNCIAS BIBLIOGRÁFICAS}

1. ACEMIOGLU, B. Adsorption of Congo red from aqueous solution onto calcium-rich fly ash, J. Colloid Interface Sci. 274, 2004, 371-379.

2. AKSU, Z., DONMEZ, G., Combined effects of molasses sucrose and reactive dye on the growth and dye bioaccumulation properties of Candida tropicallis, Process Bioch 40, 2005, 2443-2454.

3. AKSU, Z., Reactive dye bioaccumulation by Saccharomyces cerevisae, Process Biochem 38, 2003, 1437-1444.

4. AKSU, Z., TEZER, S., Equilibrium and kinetic modeling of biosorption of Remazol Black B by Rhizopus arrhizus in a batch system: effect of temperature, Process Bioch 36, 2000, 431-439.

5. AMBROSIO, S.T., CAMPOS-TAKAK, G.M., Decolorization of reactive azo dyes by Cunninghamella elegans UCP 542 under co-metabolic conditions, Bioresource Technol Lett 24, 2002, 1757-1761. 
6. ARCHIBALD, F., Lignin peroxidase activity is not important in biological bleaching and delignification of unbleached kraft pulp by Trametes versicolor, Appl Environ Microbiol 58, 1992, 31013109.

7. BALAMURUGAN, B., THIRUMARIMURUGAN, M., KANNADASAN, T., Anaerobic degradation of textile dye bath effluent using Halomonas sp., Bioresource Technology 102, Krishnankoil, 2011, 63656369.

8. BALAN, D.S.I., MONTEIRO, R.T.R., Decolourization of textile indigo dye by ligninolytic fungi, J. Biotechnology 89, 2001, 141-145.

9. BANAT, IM., NIGAM, P., SINGH, D., MARCHANT, R., Microbial decolorization of textile dye containing effluents: a review, Bioresource Technology 58, 1996, 217-227.

10. BECHTOLD, T., TURCANU, A., SCHRORR,W., Eletrochemical decolourization of dispersed indigo on boron-doped diamond anodes, Diamond Relat. Mater. 15, 2006, 1513-1519.

11. BEZALEL, L., HADAR, Y., CERNIGLIA, CE., Enzymatic mechanisms involved inphenanthrene degradation by the White rot fungus Pleurotus ostreatus, Appl Environ Microbiol 63, 1997, $2495-2501$.

12. ÇETIN, D., DONMEZ, G., Decolorization of reactive dyes by mixed cultures isolated from textile effluent under anaerobic conditions, Enzyme and Microbial Technology 38, Ankara, 2006, 926-930.

13. CHEN, K., WU, J., LIOU, D., HWANG CJ., Decolourisation of textile dyes By newly isolated bacterial strains, J Biotechnol, 101, 2003, 57-68.

14. CRINI, G., Kinetic and equilibrium studies on the removal of cationic dyes from aqueous solution by adsorption on a cyclodextrin polymer, Dyes Pigment 77, 2008, 415-426.

15. CRIPPS, C., BUMPUS, JA., Aust SD Biodegradation of azo and heterocyclic dyes by Phanerochaete chrysosporium, Appl Environ Microbiol 56, 1990, 1114-1118.

16. FERREIRA, VS., MAGALHÃES, DB., KLING, SH., da Silva, JG., Bom EPS, N-demethylation of Methylene Blue by lignin peroxidase from Phanerochaete chrysosporium, Appl Environ Microbiol, 84, 2000, 84-86.

17. FU, Y., VIRAGRAVAN, T., Fungal decolorization of dye wastewaters: a review, Bioresour Technology, 79, 2001, 251-262.

18. GANESH, R., BOARDMAN, GD., TINCHER, WC., Fate of azo dyes in sludges, Water Res., 28, 1994, 1367-1376.

19. GOTTLIEB, A., SHAW, C., SMITH, A., WHEATLEY, A., Forsythe, S., The toxicity of textile reactive azo dyes after hydrolysis and decolourisation, J Biotechnology 101, 2003, 49-56.

20. HAI, F.I., YAMAMOTO, K., FUKUSHI, K., Hybrid treatment system for dye wastewater, Crit Ver Environ Sci Technology 37, 2007, 315-377.

21. HOU, H., ZHOU, J., WANG, J., DU, C., YAN, B., Enhancement of laccase production by Pleurotus ostreatus and its use for the decolourization of anthraquinone dye, Process Biochem. Eng. J. 39, 2004,1415-1419.

22. ISPICH, 1995, Industrial safety and pollution control handbook, A joint publication of National Safety Council and Associate (Data) Publishers Pvt. Ltd., Hyderabad, 2nd edition, 2nd reprint, 451-466.

23. KAPDAN, IK., KARGI, F., MCMULLAN, G., MARCHANT, R., Effect of environmental conditions on biological decolorization of textile dyestuff by C. versicolor, Enzyme Microb Technol 26, 2000, $381-387$.

24. KAUSHIK, P., MALIK, A., Fungal dye decolourization: Recent advances and future potential, Environment International 35, 2009, 127-141.

25. KHELIFI, E., AYED, L., BOUALLAGUI, H., TOUHAMI, Y., HAMDI, M, Effect of nitrogen and carbon sources on indigo and congo red decoulorization by Aspergillus alliaceus strain 121C, Journal of Hazardou Materials, Tunis, 2009, 1056-1062.

26. KIRK, TK., FARRELL, RL., Enzymatic “combustion”, The microbial degradation of lignin, Annu Rev Microbiol 41, 1987, 465-505.

27. KNAPP, JS., VANTOCH-WOOD, EJ., ZHANG, F., Use of wood-rotting fungi for the decolourisation of dyes and industrial effluents, In: Fungi in bioremediation, Cambridge, UK: Cambridge University Press, 2001, 242-301. 
28. KNAPP, JS., ZHANG, F., TAPLEY, KN., Decolourisation of Orange II by a white-rot fungus, J Chem Technol Biotechnol 69, 1997, 289-296.

29. LIAKOU, S. PAVLOU, S., LYBERATOS, G., Ozonation of azo dyes, Wat. Sci. Tech. 35, 1997, 279-285.

30. LIBRA, J.A., BORCHERT., M., VIGELAHN, L., STORM, T., Two stage biological treatment of a diazo reactive textile dye and the fate of the metabolites, Chemosphere 56, 2004, 167-180.

31. LOPEZ, M.J., GUISADO, M.C., VARGAS-GARCIA, ESTRELLA, F.S. , MORENO, J. ,Decolourization of industrial dyes by lignolytic microorganisms isolated from compositing environment, Enzyme and Microbial Technology 40, 2006, 42-45

32. MARTINS, M.A.M., LIMA, N., SILVESTER, A.J.D., QUEIROZ, M.J., Comparative studies of fungal degradation of single or mixed bioaccessible reactive azo dyes, Chemosphere 52, 2003, 967-973.

33. MASTEN, S.J., DAVIES, S.H.R., The use of ozonation to degrade organic contaminants in wastewaters, Environ. Sci. Technol. 28, 1994, 180A-185A.

34. MEEHAN, C., BANAT, IM., MCMULLAN, G., NIGAM, P., AMYTH, F., MARCHANT, R., Decolorization of Remazol Black B using a thermotolerant yeast, Kluyveromyces marxianus IMB3, Environ Int 26, 2006, 75-79

35. MEYER, U., Biodegradation of synthetic organic colorant, FEMS Symp, 12, 1981, 371-385.

36. MOH ORCIC, M., TEODOROVIC, S., GOLOB, V., FRIEDRICH, J., Fungal enzymatic decolourisation of artificial textile dye baths, Chemosphere, 63, 2006, 1709-1717.

37. MORAES, S.G., FREIRE, R. S., DURÁN, N., Degradation and toxicity reduction of textile effluent by combined photocatalytic and ozonation processes, Chemosphere 40, Campinas, 2000, 369, 373.

38. NILSSON, I., MOLLER, A., MATIASSON, B., RUBINDAMAYUGI, M.S.T., WELANDER, U., Decolorization of synthetic and real textile wastewater by the use of white-rot fungi, Enzyme and Microbial Technology 38, Dar es Salaam, 2006, 94-100.

39. NYANHONGO, G.S., GOMES, J., GUBITZ, G.M., ZVAUYA, R.., Readd, J., Steiner, W., Decolorization of textile dyes by laccases from a newly isolated strain of Trametes modesta, Water Res. 36, 2002, 14491456.

40. O'NEILL, C., LOPEZ, A., ESTEVES, S., HAWKES, F.R., Hawkes, , D.L., WILCOX., S., Azo-dye degradation in an anaerobic -aerobic treatment system operating on simulated textile effluent, Appl Microbiol Biotechnol 53, 2000, 249-254.

41. Oxspring, DA., MCMULLAN, G., SMYTH WF., MARCHANT, R., Decolourisation and metabolism of the reactive textile dye, Remazol Black $B$, by an immobilized microbial consortium, Biotechnology Lett 18 , 1996, 527-530.

42. GANODERMAIERI, G., CENNAMO, G., SANNIA, G., Remazol Brilliant Blue R decolourisation by the fungus Pleurotus ostreatus and its oxidative enzymatic system, Enzyme and Microbial Technology 36, 2005, 17-24.

43. Peralta-ZAMORA, P., KUNZ, A., MORAES, S.G., PELEGRINI, R., MOLEIRO, P.C., REYES, J., DURAN, N., Degradation of rective dyes I: A comparative study of ozonation enzymatic and photochemical processes, Chemosphere 38, 1999, 835-852.

44. PODGORNIK, H., POLJANSEK, I., PERDIH, A., Transformation of indigo carmine by Phanerochaete chrysosporium lignolytic enzymes, Enzyme and Microbial Technology 29, 2001, 166-172

45. POINTING, SB., Feasibility of bioremediation by white-rot fungi , Appl Microbiol Biotechnol 57, 2001, 20-33.

46. PRIGIONE, V., TIGINI, V., PEZZELLA, C., ANASTASI, A., SANNIA, G., VARESE, G.C., Decolourisation and detoxi fication of textile effluents by fungal biosorption, Water Research 42, 2008, 2911-2920.

47. REDDY, CA., The potential for white rot fungi in the treatment of pollutants, Curr Opin Biotechnol 6, 1995, 320-328.

48. REVANKAR, M.S., LELE, S.S., Synthetic dye decolorization by Ganoderma sp., WR-1, Bioresourse Technology 98, 2007, 775-780.

49. RIGAS, F., DRITSA, V., Decolourisation of a polymeric dye by selected fungal strains in liquid cultures, Enzyme Microb Technology 39, 2006, 120-124. 
50. ROMERO, S., BLANQUEZ, P., CAMINAL, G., FONT, X., SARRA, M., GABARRELL, X., VICENT, T., Different approaches to improving the textile dye degradation capacity of Trametes versicolour, Bioche. Eng. J. 31, 2006, 42-47.

51. ROY, BP., ARCHIBALD, F., Effects of kraft pulp and lignin on Trametes versicolor, Appl Environ Microbiol 59, 1993, 1855-1863.

52. SUMATHI, S., MANJU, BS., Uptake of reactive textile dyes by Aspergillus foetidus, Enzyme Microb Technology 27, 2000, 347-355.

53. SWA MY, J., RAMSAY, JA., The evaluation of white-rot fungi in the decoloration of textile dyes, Enzyme Microb Technol 24, 1999, 130-137.

54. SWAMY, J., RAMSAY, JA., the evaluation of white rot fungi in the decolouration of textile dyes, enzyme Microb Technology 24, 1999, 130-137.

55. Toh, Y.-C., Yen, J.J.L., Obbard, J.P., Ting, Y.-P., Decolourization of azo dyes by white rot fungi (WRF) isolated in Singapore, Enzyme Microbial Technology 33, 2003, 569-575.

56. VANDERVIVERA, P.C., BIANCHI, R., VERSTRAETE, W., Treatment and reuse of wastewater from the textile wet-processing industry: review of emerging technologies, Journal of Chemical Technology and Biotechnology 72, 1998, 289-302.

57. WESENBERG, D., KYRIAKIDES, I., Agathos, S.N., White rot fungi and their enzymes for the treatment of industrial dye effluents, App. Environ. Microbiol. 65, 1999, 1029-1035.

58. YESILADA, O., ASMA, D., CING, S., Decolorization of textile dyes by fungal pellets, Process Biochemistry 38, Malatya, 2003, 933-938

59. YESILADA, O., Decolorization of crystal violet by fungi, World J Microb Biotech , 11, 1995, 601-602.

60. ZHANG, F., YU, J., Decolourisation of acid violet 7 with complex pellets of white rot fungus and activated carbon, Bioproc. Eng. 23, 2000, 295-301. 